\title{
21- Kültür aktarımı bağlamında yabancı dil olarak Arapça öğretimi ders kitapları örneği (B1-B2 Düzeyi)
}

Tawfik Abdo Taher AL-SHARABí1

APA: Al-Sharabi, T. A. T. (2021). Kültür aktarımı bağlamında yabancı dil olarak Arapça öğretimi ders kitapları örneği (B1-B2 Düzeyi). RumeliDE Dil ve Edebiyat Araştırmaları Dergisi, (Ö10), 352364. DOI: 10.29000/rumelide.1011954.

\section{$\ddot{O} \mathbf{z}$}

Yabancı dil öğretiminde hedef yalnızca dilin temel becerilerini ya da dil bilgisini anlatıp kazandırmak değil, aynı zamanda o dilin kültürünün öğretimidir. Çünkü, yabancı dil öğretimi aynı anda yabancı bir kültürü de getirir. Aynı zamanda kültürel unsurların öğretiminin önemi ders kitaplarındaki kültür aktarımı bağlamında araştırılırken Arapçanın yabancı dil olarak öğretimindeki ders kitapları değerlendirerek konu biraz daha açıklığa kavuşturulmak istenmektedir. Bu çalışmada dil öğretiminin aynı zamanda kültür öğretimi olduğu düşüncesinden yola çıkarak yabancı dil olarak Arapça öğretiminde kültür aktarım araçlarından olan ders kitaplarının bu süreçteki yeri ve önemi sorgulanmıştır. Arapça öğretimi bağlamında ders kitaplarında kültür aktarımı konusu, yabancı dil olarak Arapça öğretiminde kullanılan Arapça öğretim seti B1 ve B2 orta düzeyi ders kitapları esas alınarak doküman incelemesi yöntemine göre araştırılmıştır. Yabancılara Arapça öğretiminde öğretim seti B1 ve B2 orta düzeyi ders kitapları kültür aktarımı açısından incelendiğinde, hedef kültür olan Arap kültürünün yanı sıra Arap kültürü dışında farklı kültürel unsurlarında yer aldığı görülmüştür. Ders kitaplarında yer alan ünitelerde ve konularda hangi dilbilgisi ve hangi kültürün aktarımı verileceği önceden belirlenmiştir. Bu yüzden kullanımda olan yabancılara Arapça öğretimi ders kitaplarının kültür aktarımının, pratikteki ve gelenekteki Arap kültürü ile uyumlu olup olmadığının ortaya konmasına ihtiyaç duyulmaktadır. Bu çalışmanın amacı Arapçanın yabancı dil olarak öğretildiği ortamlarda, kullanılmakta olan ders kitaplarını kültür aktarımı bağlamında araştırmaktır. Böylece bir dilin yabancılara öğretimi esnasında o dile ait kültürün de öğretilmesinin o dilin öğretimine yarar sağlayacağı ve yabancılara dil öğretimi amacıyla yazılmış kitapların o dile ait kültür unsurlarının tanıtıldığı metinlerle donatılmasının kültür aktarıcısı olan dilin daha iyi öğretilmesini ve anlaşılmasını sağlayacağı belirtilecektir.

Anahtar kelimeler: Yabancı dil olarak Arapça öğretimi, ders kitapları, kültür aktarımı, kültürel unsurlar

\section{Course books example of Arabic teaching as a foreign language in the context of cultural transfer (B1-B2 Level)}

\begin{abstract}
The goal in foreign language teaching is not only to explain and gain basic language skills or grammar, but also to teach the culture of that language. Because teaching a foreign language brings a foreign culture at the same time. At the same time, while the importance of teaching cultural elements is investigated in the context of cultural transfer in the textbooks, it is desired to clarify the subject a little more by evaluating the textbooks in the teaching of Arabic as a foreign language. In this study,
\end{abstract}

Doktora, Gazi Üniversitesi, Eğitim bilimleri Enstitüsü, Yabancı Dil Olarak Türkçenin Öğretimi (Ankara, Türkiye), alsherabitawfik@gmail.com, ORCID ID: 0000-0001-8653-6364 [Araştırma makalesi, Makale kaylt tarihi: 23.09.2021kabul tarihi: 20.10.2021; DOI: 10.29000/rumelide.1011954]

Adres $\mid$ Address

RumeliDE Dil ve Edebiyat Araşturmalar Dergisi $\quad$ RumeliDE Journal of Language and Literature Studies Osmanağa Mahallesi, Mürver Çiçeği Sokak, No:14/8 Osmanağa Mahallesi, Mürver Çiçeği Sokak, No:14/8 Kadıköy - İSTANBUL / TÜRKIYE 34714 Kadıköy - ISTANBUL / TURKEY 34714 e-posta: editor@rumelide.com e-mail: editor@rumelide.com, tel: +90 505 7958124, +90 2167730616 phone: +90 505 7958124, +90 2167730616 
based on the idea that language teaching is also cultural teaching, the place and importance of textbooks, which are cultural transfer tools in teaching Arabic as a foreign language, in this process was questioned. In the context of teaching Arabic, the subject of cultural transfer in textbooks was investigated according to the document analysis method, based on the Arabic teaching set B1 and B2 intermediate level textbooks used in teaching Arabic as a foreign language. When the B1 and B2 intermediate level textbooks in teaching Arabic to foreigners are examined in terms of cultural transfer, it is seen that besides the target culture, Arab culture, it has different cultural elements other than Arab culture. It was determined in advance which grammar and which culture would be transferred in the units and subjects in the textbooks. Therefore, it is necessary to reveal whether the cultural transfer of the Arabic teaching textbooks to foreigners in use is compatible with the practice and tradition of Arabic culture. The aim of this study is to investigate the textbooks used in environments where Arabic is taught as a foreign language in the context of cultural transfer. Thus, it will be stated that while teaching a language to foreigners, teaching the culture of that language will also benefit the teaching of that language, and equipping the books written for the purpose of language teaching to foreigners with texts in which the cultural elements of that language are introduced will enable the language, which is a cultural transmitter, to be taught and understood better.

Keywords: Teaching Arabic as a foreign language, textbooks, cultural transfer, cultural elements

\section{Giriş}

Arap dili; hayal gücü, edebiyat, sarf, nahiv ve terkip özelliklerinin üstünlüğü bakımından en eski diller içinde bulunduğu için önemlidir. Zira, bu durum farklı ilim alanlarının terimlerinde de kendini gösterir. Ayrıca, Arap dili yaklaşık 280 milyon kişi tarafından konuşulduğu için dünyada en çok konuşulan diller arasında dördüncü sırada yer almaktadır. Arapçanın yabancı dil olarak öğretimi yalnızca dil bilgisinin öğretimi ya da sözcük hazinesinin aktarımı demek değildir. O dilin topluma ait kültürel kodlarının da dil vasıtasıyla karşı tarafa aktarılmasıdır. Arapçanın yabancı dil olarak öğretiminde yalnızca Arapçanın dil sistemi, dil yapılarının öğretilmesi, genel dil kurallarının gösterilmesi değil her iki kültürel aktarımın yapılarak Arap kültürünün tanıtılması da amaçlanmaktadır. Bu, Arapçanın yabancı dil olarak öğretilmesi bağlamında dikkate alınması gereken en önemli ilke niteliğindedir. Bununla birlikte kültür aktarımında bir dengenin olması da gerekir. Yabancı öğrencilere yabancı dil olarak Arapça öğretiminde bazı yöntemsel sorunlar çımaktadır. Bunlardan biri kültür aktarımı sorunudur. Bunun çözümü de yabancılara Arapça öğretirken dille birlikte o dilin kültürünün de aktarılmasıdır.

Yabancılara dil öğretimi esnasında kültürel öğeler işlenirken dikkatli olunmalıdır. Çünkü, dildeki unsurlar doğduğu kültürle çelişmemelidir. Günay'ın 2016'da yayınlanan çalışmasına göre "Yeni öğrenilen bir dilin, o dilin kültürüne uygun olarak konuşulması gereklidir. Dil ya da kültür, iletişimi de etkiler. Bu bir bakıma sınırlılıktır. Çünkü, o dil, ilgili kültür ve düşünce yapısında doğup gelişmiştir" (Günay;2016:19). Ancak, yabanc1 dil öğreten kitaplarda kültür farklı bir bölüm olarak öğrencilere sunulmalıdır. Mesela, İstanbul ders kitaplarında her ünitenin sonunda 'Kültürden kültüre' adlı bir başlık bulunmaktadır. Bu başlıklarda yabancılara başka toplumların kültürleri anlatılmaya çalışılmıştır. Ayrıca öğretilen kültür ögesi işlenen konuya uygun şekilde etkinliklere eşit oranda dağıtılmalıdır. Yani kültür ve dil arasında bağlantının var olduğu gösterilmelidir. Çünkü kültür toplumun yaşama tarzıdır. Ayrıca bireyler kendi kültürleri dışında başka bir kültürle karşılaşarak hem kendi kültürü dışında bir kültürün de olduğunu fark eder hem de yapacağı kültür karşılaştırmaları sayesinde kendi kültürünün farkına vararak kendi kültürüne farklı bakış açıları geliştirir (İşci, 2012: 33).

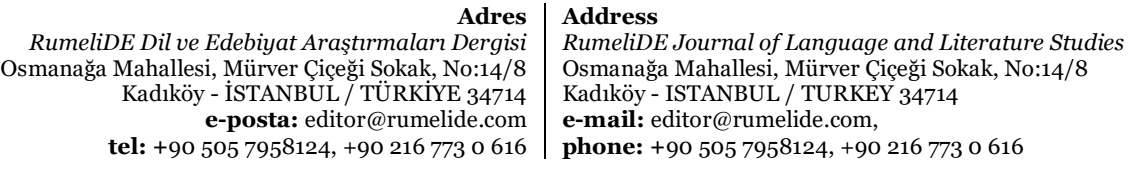


Kongar (2005: 38) kültürü, doğanın ya da tanrının yarattıklarına ek olarak insanoğlunun yarattıklarının tümü olarak nitelendirmiştir. Ona göre, her türlü araç gereç, makine, giyim-kuşam, inançlar, değerler, tutumlar bir kültürü oluşturan ögelerdir. Peck'e göre (1998) kültür, bireylerin kabul edilen ve düzenlenmiş davranışlarının tümüdür. Bu tanımdan hareketle kültürü bir grup insanı birbirine bağlayarak onları diğer insanlardan ayıran toplumsal değerler bütünü olarak değerlendirebiliriz. Hyde ve Kullman (2004: 59) da kültürü, toplumda edinilen inanç, sanat, ahlak, hukuk, geleneklerin bir bütün olarak oluşturduğu karmaşık bir yapı olarak görmüştür. Bu tanımlardan da anlaşıldığı üzere insanlar arasındaki her çeşit etkileşimlere, her türlü yapıp yaratma alışkanlıklarına, bütün 'manevi' ve 'maddesel' yapit ve ürünlerin kültür kavramına ait olduğu gözlemlenebilir (Soyşekerci, 2015: 12). Demek ki; kültür, belli bir topluluğun inançları, tutumları, gelenekleri, davranış şekilleri ve sosyal gelenekleri bütünüdür. Brooks'a (1986) göre yabancı dil öğretiminde öğrenciye sunulabilecek kültürel ögelerin bazıları şunlardır:

Selamlaşma, vedalaşma, arkadaşlar arası konuşmalar.

İnsanları tanıştırma.

Karşılıklı konuşmalarda yaşa, cinsiyete, yakınlık derecesine, sosyal statüye, resmiyete göre kullanılacak sözler ve kalıplar.

Sorulmaması gereken sorular.

Gelenekler, oyunlar, müzik, telefon konuşmaları.

Mektup yazma.

Birini davet etme, randevu verme, saatler.

Yemek yeme ve içme alışkanlıkları vb. (Brooks, 1986, 124-128).

\section{Araştırmanın amacı}

$\mathrm{Bu}$ çalışmanın amacı, Arapçanın yabancı dil olarak öğretildiği ortamlarda, kullanılmakta olan ders kitaplarını kültür aktarımı bağlamında incelemektir. Böylece bir dilin yabancılara öğretimi esnasında o dile ait kültürün de öğretilmesinin o dilin öğretimine yarar sağlayacağı ve yabancılara dil öğretimi amacıyla yazılmış kitapların o dile ait kültür unsurlarının tanıtıldığı metinlerle donatılmasının kültür aktarıcısı olan dilin daha iyi öğretilmesini ve anlaşılmasını sağlayacağı belirtilecektir.

\section{Araştırma problemi}

Yabancı dil öğretiminde en önemli basamaklardan biri öğrenilen dilin kültürünü de öğretmektir. Ancak bazen bu durum göz ardı edilmektedir. Çalışmada belirlenen kitapların B1 ve B2 seviyeleri yabancı dil olarak Arapça ders kitaplarındaki kültürel unsurların günlük yaşam, sosyal yaşam, kişiler arası ilişkiler, gelenekler ve yabancı kültürler bakımından incelemesi yapılmıştır.

\section{Sinurlılıklar}

Araştırma, B1-B2 orta seviyesi ders kitapları ile sınırlıdır. Ayrıca kitaplar günlük yaşam, kişiler arası ilişkiler, gelenekler, sosyal yaşam ve yabancı kültürler doğrultusunda belirlenen kültür aktarımı oranları açısından incelenmiştir. Kültür oranlarının seçimi konusunda belirlenen seviyelere dikkat edilmiştir. Bu ders kitapları incelenip değerlendirilirken materyal olarak yabancılar için Arapça ders kitapları kullanılmıştır.

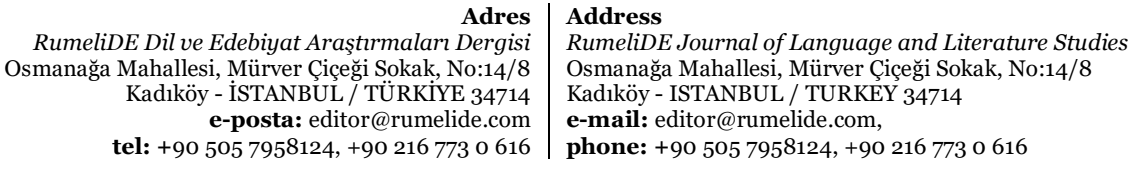




\section{Yabancı dil öğretimi ders kitapları ve kültür aktarımı}

Yabancı dil olarak Arapça öğretiminde oluşturan temellerinin hem ders kitapları hem de kültür aktarımının önemli unsurlarından biridir. Ülker'in Bayram ve Risager'den yaptığı aktarıma göre yabancı dil öğretiminde "Kültür aktarımının büyük önemi vardır; fakat kültür çok kapsamlı bir olgu olduğu için ve yabancı dil öğrenenler yine de daha çok dilin dizgesel yapılarına odaklı olduklarından kültür başlığı altında öğrenciye verilebilecek olan şeyler öğrencinin dili anlamasına yardımcı olacak nitelikte olmalıdır. (Ülker, 2007: 16-17). Aynı zamanda Arapçanın yabancı dil olarak öğretiminde kullanılan ders kitaplarının her şeyden önce öğrencilere uygun bir dil ile hedef dilin kültürü ve kültür ile ilgili ön planlardan etkinlikler anlatılması gerekmektedir. Ancak, Cortazzi ve Jin’e (1999) göre, yabancı dil öğretiminde kullanılan ders kitapları farklı görevler üstlenebilir: Bir öğretmen, bir rehber, bir kaynak, bir eğitmen, bir otorite olabilir. Aynı zamanda Arapçanın yabancı dil olarak öğretiminde kullanılan ders kitaplarının niteliğinin denetlenmesi göz ardı edilmemesi gereken önemli bir konudur. Çünkü ders kitapları, bir öğretim programı bulunmayan Arapçanın yabancı dil olarak öğretilmesi alanında program görevini üstlenmiştir. Yabancı dil öğretimindeki başlıca araçlardan biri olan ders kitaplarında salt dil bilgisi öğretimi dışında yaşam - deneyim alanları çerçevesinde kültürel kavramlar da aktarılmalı, sözü edilen amaçlara ulaşmak için karşılaştırmalı ve uygulamaya yönelik yöntemler benimsenmelidir. Kültür aktarımını kaynak kültüre, hedef kültüre ve uluslararası kültürlere dayandıran türde ders kitapları arasında ise en amaca yönelik olanları hedef kültüre ve uluslararası dayalı olanlardır çünkü bunlar aracılığıyla bir yandan öğrenilen dilin kültüründeki uygun yaşam kalıpları aktarılırken bir yandan da dünyadaki kültürel çeşitlilik yansıtılır (Özışık, 2004).

Burada önemli olan öğrencilerin dil öğrenimi hangi seviyede öğrenmek istemeleri ve hangi amaçlara yönelik kullanmak istemeleridir. Bu durum aynı zamanda öğrencilere verilecek olan eğitimi doğrudan etkilemektedir. Yabancı dil öğretiminde Arapça öğrenen birisi için dilin bütün düzeylerinde rastlanabilecek bir durumdur. Zira: bu bağlamda hem sözlü hem de yazılı anlatımda kullanılan dili mümkün olduğunca gerçek dile yaklaştırmaktadır. Yabancı öğrencilere Arapçanın yabancı dil olarak öğretiminde önemli bir unsur olan kültürlerarası ve kültür aktarımı konusu ve dillere ait kültür aktarılacaktır. Özellikle temel düzeyde (A1)'den (C1)'e kadar Arapça öğrencilere ders kitaplarındaki kültür unsurları anlatmaktadır.

İnsanlar yeni bir dil öğrenirken o toplumun düşünce yapısını, kültürünü de öğrenmektedir. Demir ve Açık'ın 2011'de yayınlanan çalışmasına göre "Yabancı dil öğrenmek, ana dilimizdeki kavramların, anlatımların karşıllğını o dilde bulup kullanmak yani sadece kuralların öğrenilmesi ve kelimelerin o dile çevrilmesi demek değildir" (Demir ve Açlk,2011:55). Yani kültür toplumu diğerler toplumlardan ayırır ve toplumlar arasındaki ilişkiyi kuvvetlendir, toplumun tanıtılmasını sağlar. Aynı zamanda Demir ve Açık'ın 2011'de yayınlanan çalışmasına göre "Yabancı dil öğrenimi bir anlamda dünyada bulunan diğer toplumların dünyaya bakış açlarını, düşünce ve değer sistemlerini anlamak için yapılan bir uğraştır" (Demir ve Açık,2011:55).

\section{Yabancılara Arapça öğretiminde ölçme ve değerlendirme}

Kılıçkaya’ya (2004) göre ders kitaplarındaki kültürel içeriği incelerken öğrencilerin ihtiyaçları ve öğretmenlerin rolü dışında da dikkat edilmesi gereken konular vardır. Her ders kitabının kendine özgü bir programı bulunmaktadır. Yabancı dil olarak Arapça sınıflarında anadil konuşucuları için hazırlanmış herhangi bir dil öğretme amacı taşımayan özgün metinleri kullanmak için yapılması gereken işlemler ve yabancı dil olarak Arapça öğretiminde kullanılan metinlerin özgün metinlerin içinden seçilmesinin 
önemi işlenmiştir. Özgün metinler herhangi bir dil öğretme amacı taşımaksızın anadil konuşucuları için üretilmiş metinlerdir. Diğer taraftan uyarlanmış metinler ise öğrencilerin dil düzeylerine göre değiştirmeler sonucu ortaya çıkmış metinlerdir. Öğretimde özgün metin kullanılmasının gerektiğini savunanlara göre uyarlanmış metinler, dilin doğal kimliğini yok sayarak onu olmadığı bir biçime dönüştürürler. Bu haliyle uyarlanmış metinler öğrencilere yapay gelebilir. Bu da onları dil öğrenmekten uzaklaştırabilir.

Ergin'in 200o'de yayınlanan çalışmasının 25. Sayfasında "Yabancı dil öğretiminde kullanılacak olan yöntemlerin, öğretilecek dilin özelliklerine ve öğrenenlerine göre uyarlanmasının daha faydalı olacağı düşünülmektedir" demektedir. Yabancı dil olarak Arapça öğretiminde geleneksel ölçme araçlarıyla birlikte tamamlayıı ölçme araçları da kullanılabilir. Ölçme sonuçlarına göre yapılacak değerlendirme çalışmalarında dil becerisinin tüm alanlarıyla ilgili öğrencilere geri dönütler verilmelidir. Aynı zamanda Engin'in çalışmasında da "Dili, zamanla gelişen, değişen, kendini güncelleyen ve "kendine mahsus kanunları olan ve ancak bu kanunlar çerçevesinde gelişen canlı bir varlık" (Ergin, 2000) olarak ele alırsak dili öğrenmek ve öğretmek için kullanacağımız yol ve yöntemleri de o özelliklere göre ele almak faydalı olacaktır". Her beceri alanı içindeki testlerde sorular ve sınav malzemeleri basitten karmaşığa, kolaydan zora doğru sıralanmalıdır. Dört temel dil becerisi için ayrı ayrı ölçme araçlarına başvurulabilir. Dinlemede öğrenciye bir metin okuyarak anladıklarını yazması istenebilir. Yazmada kısa bir kompozisyon yazdırılabilir. Sözlü anlatım ve karşılıklı konuşmada günlük yaşam durumları drama yaptırılabilir. Ölçme ve değerlendirmeden sonra ölçme araçlarının geçerliği ve güvenirliği sınanmalı, madde analizleri yapılmalıdır.

Yabancı dil sınıflarında kültür ögelerinin etkin biçimde aktarımında üzerinde durulması gereken bazı noktalar şunlardır (Dunnett, Dubin ve Lezberg, 1986: 157-160):
A. Ders izlencesi hazırlanırken kültürel ögelerin aktarımına da tıpkı dil bilgisi ve sözcük öğretiminde olduğu gibi birincil derecede önem verilmelidir.
B. Yabancı dil dersleri kültürel ögelerin aktarımını etkin kılacak zamanı sağlayacak şekilde düzenlenmeli ya da bu aktarım için ayrı dersler oluşturulmalıdır.
C. Kültür konusu öğretmen yetiştirme programlarında özel olarak vurgulanmalıdır.
D. Öğretmenler ders kitaplarını seçerken kültürel ögelerin başarılı bir şekilde verilip verilmediğini iyice incelemelidir.

Ancak, baktığımız zaman yabancılara Arapça öğretiminde kullanılacak ölçme araçlarında bulunması gereken bazı özellikler şunlardır:

- Ölçmede amaç sadece ilgili özelliğin bulunuşluk derecesini saptamaktır.

- Kullanılan sözcükler öğrencinin sözcük dağarcığına uygun bir şekilde olmalıdır.

- Kullanılan sözcükler günlük yaşamda sıklıkla kullanılan sözcükler ve cümleler olmalıdır.

- Öğrencilere soru sorarken, kullanılacak sorular çok uzun olmamalıdır.

- Her beceri alanı içindeki testlerde sorular ve kolaydan zora doğru sıralanmalıdır.

\section{Arapça öğretim ders kitaplarında kültür varlığı}

Kültür, dil öğrenmenin değerlendirmesinde ortak ölçütleri ortaya çıkarmaktadır. Aynı zamanda kültür, dil ders kitaplarının değerlendirilmesinde ortak çalışmaların ve standartların tanımını geliştirilen yeni standartların öğretilmesini sağlar. Arapça öğretiminde kullanılan kitapların, insanlara ana dilde konuşulmayan kelimelerin

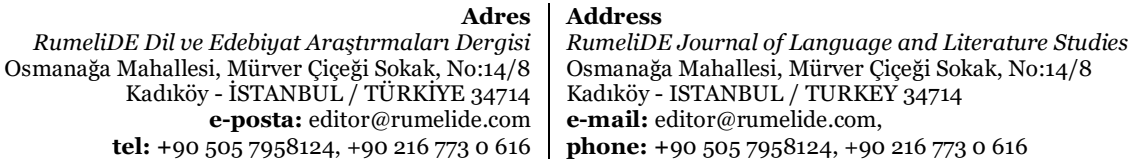


yazılmasının öğretilmesin de temellerinden biridir. Dolayısıyla, kültürün dilin bir tamamlayıcısı olduğunu ve kültürün dil öğreniminin nihai hedeflerinden biri olduğunu anlamaktayız. Arapça, Arap kültürlerini tüm boyutlarıyla ayırmanın mümkün olduğuna inanmamaktadır. Arapça kitaplarında anlatılan kültürlerin üç tane türü vardır. Kültür türlerinden İslam kültürü, yerel kültür ve Arap kültürüdür. Arap kültürü; Arap uygarlığına ait olan çağdaş halk grubunun sanatsal ve bilimsel gerçekleri ile faaliyetlerinin toplamı anlamına gelmektedir. İslam kültürü; inançlar, kavramlar, ilkeler, davranış değerleri ve kalıpları anlamına gelmektedir. Arapça ders kitaplarında en çok bulunan İslam kültürüdür. Küresel ya da yerel kültür; küresel düzeyde gerçekler ve olaylar anlamına gelir ve modern kültür ve iletişim alanlarındaki en son gelişmeler küresel kültür konusudur. Bu kültür fazla Arapça ders kitaplarında fazla bulunmamaktadır. Arapça ders kitaplarına baktığımız zaman yabancılara bütün kültürün türleri aktırılmamaktadır.

Yabancllar için Arapça dil öğretim kitaplarındaki alt standartların analizi "Eğitim kültürü"

- Öğretmenin kültürel konuları öğretmek için kitaplarda net bir plan yazması gerekmektedir.

- Kültürel temalar farklı seviyelere göre bölünmektedir.

- Kitap okuyucusunun yeteneklerini geliştirmek için kültürel modeller bulunması gerekmektedir.

- Yazar, Arap İslam kültürü kavramlarını kontrol eder. Çünkü, İslam kültürü bütün Arapça öğretimi kitaplarında bulunabilmektedir.

- Yazar, Arap kültürü ile ilgili kavramları belirtmek için doğru kaynaklara başvurmaktadır.

- Yazarın zamanın son gelişmelerini takip etmesi gerekmektedir.

- Kitapların, küresel kültürel ve İslami konuların konumları, kelimeleri ve yapıları içerisindeki tanıtımını yapması gerekmektedir.

Yabancllar için Arapça öğretim kitaplarındaki alt standartların analizi "Kültürel içerik"

- Kitaplarında Arap, İslam, yerel ve küresel kültürleri içermektedir.

- Arap kültürü ile İslam kültürü arasındaki fark kitaplarda gösterilmektedir.

- Kitaplarda, Arap ve İslam kültürel kavramları metinlerde bütünleşecek şekilde sunulmaktadır.

- Arapça ders kitapları Arap-İslam kültürünün gerçek modellerini içerir; Nitekim kitaplar ünlü insanlar, ülkeler, haritalar ve Kur'an sayfaları gibidir.

- Kitapların öğrencilerin kültürü ve düzeylerine uygun olması gerekmektedir.

- Kitaplar farklı düzeylerde farklı kültürler sunumunu dikkate alır.

- Kitaplar, dil ve kültür arasındaki bağlantıyı ele alır.

Yabancı öğrencilere Arapça dil öğretimi kitaplarında Kültürel İçeriğin Bölümü'nde analiz edilen ve onu öğreten kriterlerin 14 tane olduğunu keşfetmekteyiz.

\section{Bulgular ve yorumlar}

Baktığımız zaman Yabancı dil öğretiminde kültür aktarımının en iyi kaynağı olan ders kitapları, Avrupa Dilleri Ortak Çerçeve Metnine göre; başlangıç olarak A1 ve A2'yi, orta düzey olarak B1 ve B2'yi, orta düzey olarak C1 ve C2'yi ileri seviye olarak gruplandırmıştır. Yabancı dil öğretiminde en temel materyalleri, okuma-anlama metinleri ve bu metinleri destekler ve tamamlar nitelikteki ders kitapları oluşturur. Okuma-anlama metinleri ve yabancı dil öğretim sürecini destekleyici ders kitapları, okuma-

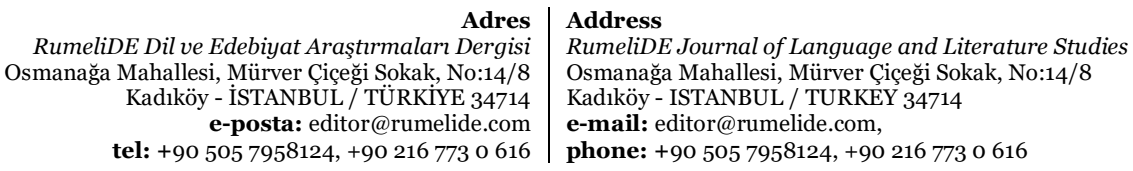


anlama becerilerinin ve diğer dil becerilerinin (Okuma-anlama, konuşma, dinleme ve yazma) de kazandırılması için önemlidir.

$\mathrm{Bu}$ çalışmada ele alınan Arapça öğretim seti ders kitaplarının B1 ve B2 orta seviyesi ünite içeriği ele alınmıştır. Üniteler işlendiği konu başlıklarına göre sınıflandırılmış. Aynı zamanda bu çalışmanın sınırlılık kısmında selamlaşma ve davranışlar, aile yapıları ve kuşaklar arası ilişkiler, misafir etme, ikram ve hediyeler bakımından Arapça ders kitapları orta B1-B2 seviyesi kitaplarının nitel açıdan tespitini amaçlayan bu çalışma betimsel nitelikli bir çalışmadır. Aynı zamanda önemli olan o kültürün taşıyıcısı olan dili öğretirken kültür unsurlarını da vermektir.

Arapça öğretiminde kullanılan ders kitaplarının ünitelerine bakıldığında B1 ve B2 seviyelerinde genellikle o kültüre ait yeme, içme, çalışma saatleri, yaşam koşullarına fazla yer verilmemiştir. Aynı zamanda kültürel ögelerin aktarımında ders kitapları birinci derecede önemli olmasına rağmen tek başına yeterli değildir. Ders kitaplarının yanında konuşma etkinliklerinde, resimlerde de yer verilmesi gerekir.

Zira; öğrenilen dil Arapçaysa Arap kültüründe misafir ağırlama, ikram etmeyle ilgili bilgi verildikten sonra Arap ailelerinin misafir ağırlama şekilleriyle ilgili resimlerle desteklenmelidir. Arapça ders kitapları Arapçanın yabancı dil olarak öğretimde birçok hem özel kurumun hem de devlet kurumun kullandığı bir kaynaktır. Arapça ders kitaplarını sürekli olarak yenileyen değişime ayak uyduran ve geleneksel dil öğretim yöntemleriyle iletişimsel yöntemi birleştirerek kitapları hazırlamıştır.

Özellikle son yıllarda dil öğretiminde kültürün tanıtılmasına daha çok ağırlık verildiği için Kültürlerarası İletişim Odaklı Yaklaşım (Intercultural Communıcatıon Approach) daha çok tercih edilmektedir. Kitap orta düzey 16 üniteden oluşmaktadır.

Arapça ders kitapların B1-B2 (Orta Düzey) Üniteleri
1. Sağlık Hizmeti
2. Yeniden yaratma
3. Evlilik
4. Şehirde yaşamak
5. Ĕ̆itim- Öğretim
6. Meslekler
7. Arapça
8. Ödüller
9. Dünya küçük bir köy
10. Temizlik
11. İslam
12. Gençler
13. İslam dünyası
14. Güvenlik
15. Kirlilik
16. Enerji

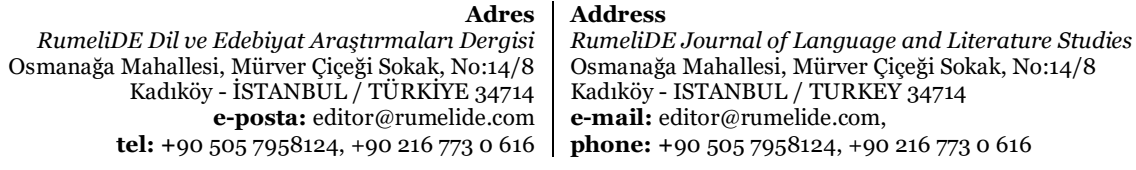


Yabancılar için Arapça öğretimi ders kitabı orta seviyeleri B1-B2 setleri şu ölçütler doğrultusunda incelenmiştir. Ayrıca kitaplar kişiler arası ilişkiler doğrultusunda belirlenen üç alt öğeye (selamlaşma ve davranışlar, aile ilişkileri ve kuşaklar arası ilişkiler, misafir etme ikram ve hediyeler) göre incelenmiştir.

Kitaplarda yer alan okuma, yazma, dinleme, konuşma becerileri belirlenen kültürel özellikler bakımından taranmıştır. Tespit edilen kültürel öğelerin bir bütün olarak değerlendirilmesi için tablolar halinde sunum yapılmıştır.

$\mathrm{Bu}$ ders kitapların yabancılara dört temel becerileri kullanarak anlatılması gerekmektedir. Kaynak tarayarak ve ders kitapları B1 ve B2 incelemesi yapılarak uygulamaların değerlendirilmesi gerekli kılınmıştır. Bu kapsamda incelenen yabancı dil olarak Arapça ders kitaplarında önemli noktalar tespit edilmiştir.

Yabancı dil olarak Arapça ders kitaplarındaki kültürel unsurları 5 ana başlık etrafında incelemiştir:

1. Günlük yaşam

2. Sosyal yaşam

3. Kişiler arası ilişkiler

4. Gelenekler

5. Yabancı Kültürler

Araştırmada kültürel ögeler analiz edilirken tasnifleme yoluna gidilmiştir. Bu tasniflendirme sonucunda B1-B2 seviyesindeki kültürel aktarımlar değerlendirilerek her biri ayrı tablo haline getirilmiştir.

Tablo 1: Kültürel aktarım tablosu

\begin{tabular}{|c|c|c|c|c|}
\hline $\begin{array}{l}\text { Alt } \\
\text { Öğe }\end{array}$ & 1.Günlük yaşam & 2.Sosyal yaşam & 3. Kişiler arası ilişkiler & 4.Gelenekler \\
\hline A & Yiyecek-İçecek & Yasaklar & $\begin{array}{l}\text { Selamlaşma ifade ve } \\
\text { davranışları }\end{array}$ & $\begin{array}{l}\text { Sözlü } \\
\text { anlatımlar ve } \\
\text { sözlü } \\
\text { gelenekler }\end{array}$ \\
\hline B & $\begin{array}{l}\text { Yemek zamanları, Sofra } \\
\text { adabı }\end{array}$ & $\begin{array}{l}\text { Güzel hareketler ve } \\
\text { alkış }\end{array}$ & $\begin{array}{l}\text { Aile yapıları ve ilişkileri, } \\
\text { kuşaklar arası ilişkiler }\end{array}$ & $\begin{array}{l}\text { Özel günler ve } \\
\text { gelenekler }\end{array}$ \\
\hline $\mathrm{C}$ & $\begin{array}{l}\text { Boş zaman etkinlikleri, } \\
\text { Hobileri }\end{array}$ & Diğerleri & Kişiler & $\begin{array}{l}\text { Doğum, } \\
\text { Evlilik } \\
\text { gelenekleri }\end{array}$ \\
\hline $\mathrm{D}$ & $\begin{array}{l}\text { Resmî tatilleri-Çalışma } \\
\text { zamanları }\end{array}$ & - & Dinî gruplar arası ilişkiler & $\begin{array}{l}\text { Toplumsal } \\
\text { uygulamalar, } \\
\text { Batıl inançlar }\end{array}$ \\
\hline $\mathrm{E}$ & $\begin{array}{l}\text { Yeme ve içme } \\
\text { alışkanlıkları }\end{array}$ & - & İkram ve hediyeler & $\begin{array}{l}\text { Halk bilgisi, } \\
\text { evren ve doğa } \\
\text { ile ilgili } \\
\text { uygulamalar }\end{array}$ \\
\hline $\mathrm{F}$ & Spor & - & Diğerleri & Diğerleri \\
\hline $\mathrm{H}$ & Müzik & - & - & - \\
\hline
\end{tabular}

Tablo 2: B1-B2 kitapları ünite başlıkları ve kazanımı

\begin{tabular}{lll}
\hline Ünite & Konu Başlıkları & Ünite Kazanımı \\
\hline 1 & Sağlık hizmeti & Genel olarak öğrencilere sağlık hizmetleri anlatılmıştır. \\
\hline
\end{tabular}

\begin{tabular}{r|l} 
Adres & Address \\
RumeliDE Dil ve Edebiyat Araştırmaları Dergisi & RumeliDE Journal of Language and Literature Studies
\end{tabular}

Osmanağa Mahallesi, Mürver Çiçeği Sokak, No:14/8 $\quad$ Osmanağa Mahallesi, Mürver Çiçeği Sokak, No:14/8

Kadıköy - ISTANBUL / TÜRKIYE 34714 Kadıköy - ISTANBUL / TURKEY 34714

e-posta: editor@rumelide.com e-mail: editor@rumelide.com,

tel: +90 505 7958124, +90 2167730616 phone: +90 505 7958124, +90 2167730616 


\begin{tabular}{|c|c|c|}
\hline 2 & Yeniden yaratma & $\begin{array}{l}\text { Öğrencilere hobiler ilgili bilgi verilmiş ve icat etmek için ne yapılması } \\
\text { gerektiği hakkında bilgi verilmiştir. }\end{array}$ \\
\hline 3 & Evlilik & $\begin{array}{l}\text { Arapların geleneksel görüşlerine yer verilerek ve Arapların geçmişten } \\
\text { günümüze devam eden değerlerle alakalı hakkında bilgi vermek } \\
\text { amaçlanmıştır. }\end{array}$ \\
\hline 4 & Şehirde yaşamak & $\begin{array}{l}\text { Yaşam ve yaşamın akıp geçmesi üzerine değerlendirmeler ele } \\
\text { alınmıştır. }\end{array}$ \\
\hline 5 & Ĕ̆itim-Öğretim & $\begin{array}{l}\text { Ĕ̆itim ve Arap ülkelerinde eğitimin nasıl gerçekleştiğine dair bir ön } \\
\text { fikir vermek amaçlanmıştır. }\end{array}$ \\
\hline 6 & Meslekler & $\begin{array}{l}\text { Bireyin meslek hayatında ilerleyişi ve Arap ülkelerde yaşam konuları } \\
\text { ele alınmıştır. }\end{array}$ \\
\hline 7 & Arapça & Yabancı öğrencilere Arapça hakkında bilgi verilmiştir. \\
\hline 8 & Ödüller & $\begin{array}{l}\text { Öğrencilere yarışmalara katılmak ve ödülleri kazanmak için bilgi } \\
\text { vermek amaçlanmıştır. }\end{array}$ \\
\hline 9 & Dünya küçük bir köy & $\begin{array}{l}\text { Bazen Fiziksel, ruhsal ve zihinsel engellilerin dünya genelindeki } \\
\text { problemlerine dikkat edilmesini amaçlamıştır. }\end{array}$ \\
\hline 10 & Temizlik & $\begin{array}{l}\text { Öğrencilerle temizlik kuralları ile ilgili sohbet edilir. Mesela, yemek } \\
\text { öncesi ve sonrası neler yapılması gerektiği hakkında bilgi verilmiştir. }\end{array}$ \\
\hline 11 & İslam & $\begin{array}{l}\text { Öğrencilere temel dini bilgiler, din kültürü ve ahlak bilgisi betimleyici } \\
\text { yaklaşımla öğretilmeye çalışılmıştır. }\end{array}$ \\
\hline 12 & Gençler & $\begin{array}{l}\text { Hayat olaylarına karşı insanların vermiş olduğu mücadele hakkında } \\
\text { bilgi verilmiştir. }\end{array}$ \\
\hline 13 & İslam Dünyası & $\begin{array}{l}\text { İslam Dünyası nasıl ve kimler kurulduğu açıklanmış. İslam ilgili bazı } \\
\text { bilgiler öğrencilere anlatılmaya çalışılmıştır. }\end{array}$ \\
\hline 14 & Güvenlik & $\begin{array}{l}\text { Öğrencilere güvenli ortamda yaşamaya yönelik durumlar } \\
\text { sunulmuştur. }\end{array}$ \\
\hline 15 & Kirlilik & Öğrencilere medeniyet ve çevre temizliğine dair bilgiler verilmiştir. \\
\hline 16 & Enerji & $\begin{array}{l}\text { Öğrencilere enerji yönetiminde karmaşık problemlere hem sözlü hem } \\
\text { de yazılı çözümler anlatılmıştır. }\end{array}$ \\
\hline
\end{tabular}

Arapça ders kitabındaki ünitelerin belirlenen kültür ögeleri bakımından uyumuna da bakılmıştır. Bu değerlendirme sonucunda, orta seviye (B1-B2) kitaplarında kültürel ögelerden az yararlanıldığı tespit edilmiştir. Bu Arapça ders kitabının 16 ünitesiyle bağdaştırılmaya çalışılmıştır. Fakat incelenen kitaplarda belirlenen kültürel ögeler, ünitelerde yoğun bir şekilde aktarılmamıştır. Sadece birkaç ünitede işlenmiştir.

Araştırmada yapılan incelemeler sonucunda bulunan kültürel sonuçlar tablo halinde tasniflenmiştir. Bu tablodan alınan sonuçlara göre aşağıda verilen örneklemler şu şekildedir:

Tablo 3: Cümle içerisinde kültürel unsur örnekleri (B1-B2)

\begin{tabular}{lll}
\hline Alt öğeler & $\begin{array}{l}\text { KÜLTÜR ÖĞELERİN AKTARILIŞ ŞEKLİ } \\
\text { (Cümle İçerisinde) }\end{array}$ & $\begin{array}{l}\text { Kitaptaki } \\
\text { yere (Sayfa) }\end{array}$ \\
\hline Günlük yaşam & Aleykümselam Ali kardeşim & 15 \\
\hline Kişilerarası ilişkiler & $\begin{array}{l}\text { Öğrencilerimiz isterlerse buralarda kahvaltı yapıp akşam } \\
\text { yemeğini yiyebilirler. }\end{array}$ & 18 \\
\hline Sosyal yaşam & Mehmet'le Hüseyin selamlaştılar. & 19 \\
\hline Kişilerarası ilişkiler & Merhaba Fatıma hoş geldiniz. & 21 \\
\hline
\end{tabular}

Adres

RumeliDE Dil ve Edebiyat Araştırmaları Dergis Osmanağa Mahallesi, Mürver Çiçeği Sokak, No:14/8 Kadıköy - ISTANBUL / TÜRKIYE 34714 e-posta: editor@rumelide.com tel: +90 $5057958124,+902167730616$
Address

RumeliDE Journal of Language and Literature Studies

Osmanağa Mahallesi, Mürver Çiçeği Sokak, No:14/8

Kadıköy - ISTANBUL / TURKEY 34714

e-mail: editor@rumelide.com,

phone: +90 5057958124, +90 2167730616 


\begin{tabular}{|c|c|c|}
\hline Kişilerarası ilişsiler & $\begin{array}{l}\text { Sevgili Ali ve Fatıma, bu karşılama ve yemek için çok teşekkür } \\
\text { ederim. }\end{array}$ & 24 \\
\hline Kişilerarası ilişkiler & Size bir hediye verirlerse, paketi açın ve "çok beğendim" deyin & 28 \\
\hline Kişilerarası ilişkiler & $\begin{array}{l}\text { Karşısındaki kişi ile aynı fikirde olup olmadığını kibarca ifade } \\
\text { eder. }\end{array}$ & 30 \\
\hline Gelenekler & $\begin{array}{l}\text { Araplar sizi seve seve evine davet edecektir, pek çok Arap evinde } \\
\text { içeriye girerken ayakkabı çıkarmak gerekir. }\end{array}$ & 32 \\
\hline Kişilerarası ilişkiler & Karşısındaki kişiye fikirlerini sorar. Daha fazla tanıdık olmayan kişilere & 34 \\
\hline Kişilerarası ilişkiler & $\begin{array}{l}\text { İnsanların kişisel ve diğer davranışlarındaki değişim ve gelişimden } \\
\text { bahseder. }\end{array}$ & 35 \\
\hline Gelenekler & Bayramlarda gelen misafirlere çikolata ve tatlı ikram edilir. & 38 \\
\hline Gelenekler & $\begin{array}{l}\text { Arap ülkelerinde düğünler genelde perşembe günü başlar ve 3-4 gün } \\
\text { sürer. }\end{array}$ & 40 \\
\hline Sosyal yaşam & Genel olarak bekara kiralık ev vermemektedir. & 44 \\
\hline Sosyal Yaşam & $\begin{array}{l}\text { Çoğunlukla Araplar emekli olmamaktadır. Çünkü, genel olarak şirket } \\
\text { sahipleridirler. }\end{array}$ & 47 \\
\hline Gelenekler & Sohbet sırasında evin sahibi misafirlere, su, içecek ve tatlı ikram eder. & 52 \\
\hline Kişilerarası ilişkiler & Biz komşularımızla her sabah selamlaşıyoruz. & 58 \\
\hline Kişilerarası ilişkiler & $\begin{array}{l}\text { Anne, baba, kızlar, damatlar, oğullar, gelinler ve torunlar aynı çatı } \\
\text { altında yaşmaktadır. }\end{array}$ & 64 \\
\hline Kişilerarası ilişkiler & $\begin{array}{l}\text { Karşısındaki kişi ile aynı fikirde olup olmadığını kibarca ifade } \\
\text { eder. }\end{array}$ & 67 \\
\hline Gelenekler & $\begin{array}{l}\text { Bayramlarda akrabalar özel yemekler yapıyorlar ve o gün bütün aile } \\
\text { beraber o yemekleri yiyor. }\end{array}$ & 72 \\
\hline
\end{tabular}

Baktığımızda orta seviye Arapça kitapları (B1-B2) yabancı bir kişinin gözünden belirlenen kültür ögelerine dair ifadelere yer vermemiştir. Yani Arapça kitaplarında çok fazla yabancılara kültür aktarılmamıştır. Aynı zamanda kitapların kültür aktarımı açısından değerlendirilmesine geldiğimizde, Arapça ders kitapları B1-B2 kitaplarının Yabancı dil olarak Arapça öğrenen öğrenicilerin Arap kültürüne ait bulgulara rastlayamayacağı kitaplardır. Bununla birlikte kitapların her ünite sonunda "Kültürden Kültüre” başlıklı bir bölümün bulunmamaktadır. Yani bu bölümlerde yabancı dil olarak Arapça öğrenen kişilerin hem öğrendikleri dilin kültürüne ait özellikleri hem de kendi kültürlerine ait özellikleri tespit etmeleri dili öğrenme açısından önemlidir. En çok kültürel öge aktarımının olduğu kitaplardaki metin, alıştırma veya uygulamalarda özel günlere ve bu günlerdeki geleneksel etkinliklere yer verilmiş̧ir.

Çalışmada belirlenen kitapların B1 ve B2 orta seviyelerinin kültürel unsurları 5 ana başlıkta incelenmiştir. Bu 5 ana başlıktan biri olan kişilerarası ilişkilerin kitaplarda diğer unsurlardan daha fazla yer kapladığı tespit edilmiştir. Bunun yanı sıra tabloda sunulan verilerin Arapçayı öğrenen yabancı öğrencilere faydalı olup olmadığına bakılmıştır.

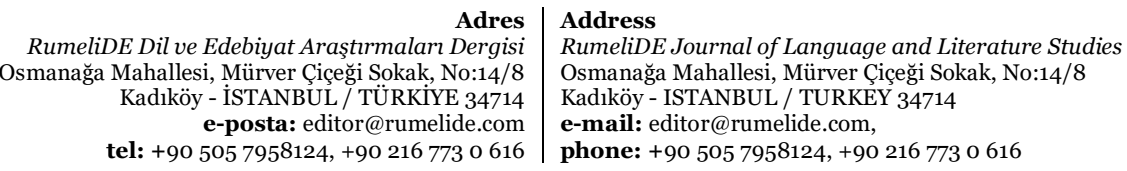


Tablo 4: Kültür aktarım oranları (B1-B2)

Yabancılara Arapça Öğretiminde Ders kitapları (B1-B2)

Kültür Aktarımı Oranları

\begin{tabular}{lll}
\hline & Orta Seviye Ders Kitapları (B1-B2) & \\
\hline Günlük Yaşam & $\mathrm{F}$ & $\%$ \\
\hline Kişiler Arası İlişkiler & 25 & 11.9 \\
\hline Gelenekler & 67 & 30.0 \\
\hline Sosyal Yaşam & 59 & 26.6 \\
\hline Yabancı Kültürler & 19 & 8.1 \\
\hline Toplam & 52 & 23.4 \\
\hline
\end{tabular}

Tablo 4’e göre günlük yaşama ait kültürel unsurların oranı orta seviye B1 ve B2 ders kitaplarında \%11,9; kişiler arası ilişkilere ait kültürel unsurların oranı orta seviye B1 ve B2 ders kitabında \%30.0; gelenekler alana ait kültürel unsurların oranı orta seviye B1 ve B2 ders kitaplarında \%826,6; sosyal yaşam alanına ait kültürel unsurların oranı orta seviye B1 ve B2 ders kitaplarında \%8,1; yabancı kültürel unsurlara bakıldığında ise, orta seviye B1 ve B2 ders kitaplarında \%23,4 olarak gerçekleşmiştir. Bu verilerden hareketle orta seviye B1 ve B2 ders kitabında yerel kültürel unsurların (Günlük Yaşam, Kişiler Arası İlişkiler; Sosyal yaşam) aktarım oranları birbirinden farklı olsa da genellikle dengeli olarak verildiği görülmektedir. Yerel kültürel unsurlardan sosyal yaşam alanına ait kültürel unsura kitaplarda rastlanmamıştır. Bu kitaplar içinde kültürel aktarım açısından bir eksiklik olarak görülebilir. Ayrıca, yabancı kültürel unsurların kitaplarda yeterli düzeyde olmadığı tespit edilmiştir.

\section{Sonuç, tartışma ve öneriler}

Çalışmada Yabancılara Arapça ders kitaplarında aktarllan kültür ve kültürel ögeler incelenerek ayrıntıları sunulmuştur. Aynı zamanda Arapça ders kitabındaki ünitelerin belirlenen kültür ögeleri bakımından uyumuna da bakılmıştır. Bu değerlendirme sonucunda, orta seviye (B1-B2) kitaplarında kültürel ögelerden az yararlanıldığı tespit etmiştir. Aynı zamanda kitaplarda kaynak kültür ve kültürün karşılaştırılması şeklinde olan kültür aktarımına yer verildiği saptanmıştır. Bu nedenle Arapça ders kitabının 16 ünitesiyle bağdaştırılmaya çalışılmıştır. Fakat incelenen kitaplarda belirlenen kültürel ögeler bakımından ünite sıralamasında az olduğunu göstermektedir. Fakat Arapça ders kitabında yapılan tespitlerde misafir ağırlamanın ayrı bir kültür ögesi taşımadığı ve eve gelen misafirin ev üyelerinden farklı olarak ayrı bir öneme sahip olmadığı görülmüştür. Sonuç olarak kitaplarda kültürel ögeler bakımından farklılık olduğu gibi birkaç ünite dışındaki üniteler bakımından da farklılık olduğu görülmüştür.

Aynı zamanda yabancılara Arapça öğretimi B1-B2 seviyesi ders kitapları, kültür aktarımı açısından incelendiğinde, Arap kültürünün öğrencilere farklı yönleriyle anlatıldığı ve Arapça öğretmeyi hedeflediği öğrencilere kültür aktarmada başarı sağlayabilecek şekilde olduğu görülmüsstür. Bu durum kültür aktarımı açısından uygun olsa da öğrencilerin kültürlerarası iletişim kazanması ve farklı kültürler oluşturmasını tam olarak sağlayamamaktadır. Aynı zamanda Arapça bilmeyenlere Arapça öğretme

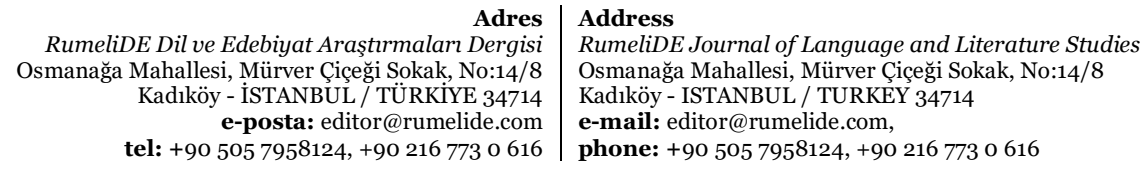


programlarında kültür varlığının önemi, ancak belki de aşağıdakileri de içeren sebeplerden ötürü hak ettiği dikkati almadığını görmekteyiz:

- Kültür öğretmek için zamanı olmadığını iddia etmesi.

- Kültürün anlaşılmasının doğal olarak edinileceği algısı.

- Kültür öğrenmenin dil ediniminden bağımsız olarak görülmesi.

- Kültürün yabancılara öğretiminin dil ile bağımlı olmaması.

\section{Tespit edilen bulgular bağlamında şu önerilerde bulunulabilir:}

1. B1-B2 seviyede diğer dilleri konuşanlara Arapça öğretimi kitabının içeriği için bir standartlar listesi oluşturmalıdır.

2. B1-B2 Arapça kitabın içeriğindeki güçlü ve zayıf yönleri belirlemelidir.

3. Öğrenciye ve bireysel farklılıklarına uygun bir şekilde dinleme içeriği sağlamalıdır.

4. Yabancılara Arapça öğretimi kitaplarının içeriğinin yeniden gözden geçirilmesi gereklidir.

5. Yabancı dil öğretiminde yoğun bir şekilde kültüre de yer vermek gereklidir.

6. Yabancı dil öğreten kitaplarda kültür farklı bir bölüm olarak öğrencilere sunulmalıdır.

7. Öğreten kitaplarda öğretilen kültür öğesi işlenen konuya uygun şekilde yabancılara öğretilmelidir.

8. Yabancılara Arapça öğretimi ile ilgili ortak bir öğretim programı hazır olması gerekmektedir.

\section{Kaynakça}

Brooks, N. (1986). Culture in the classroom. In J.M. Valdes (ed.), Culture Bound. Bridging the cultural gap in language teaching. Cambridge: Cambridge University Press, 123-128.

Cortazzi, M., Lixian, J. (1999), ,Cultural Mirrors', Culture in Second Language Teachingand Learning, Ed. by. Eli Hinkel, Cambridge, Cambridge UniversityPress, pp. 196-219.

Demir, A., Açık, F. (2011). Türkçenin Yabancı Dil Olarak Öğretiminde Kültürlerarası Yaklaşım ve Seçilecek Metinlerde Bulunması Gereken Özellikler. Tübar-XXX, s.52-72

DUNNETT, S. C.; DUBIN F.; LEZBERG A. (1986). "English Language Teaching from an Intercultural Perspective”, İçinde: Culture Bound (Ed. Joyce Merrill Valdes), Cambridge University Press, pp. 148-160.

Ergin, M. (2000). Türk Dil Bilgisi. (3. Baskı). İstanbul: Bayrak Basım Yayım Dağıtım.

Günay, V. Doğan (2016), Kültür bilime Giriş Dil, Kültür ve Ötesi... Papatya $\quad$ Yayıncllı: İstanbul.

Haley, M. Hall, A., Theresa Y.: (2004), Content-Based Second Language.

İşci, Cenan (2012), Türkçenin Yabancı Dil Olarak Öğretiminde Kullanılan "Yeni Hitit” Ders Kitabının Dört Temel Dil Becerisi ve Kültür Açısından İncelenmesi, Dokuz Eylül Üniversitesi Eğitim Bilimleri Enstitüsü Yabancı Dil Olarak Türkçe Öğretimi Anabilim Dalı, Yayımlanmamış Yüksek Lisans Tezi, İzmir.

Kılıçkaya, F. (2004). Guidelines to evaluate cultural content in textbooks. The Internet TESL Journal, 10(12), 38-48.

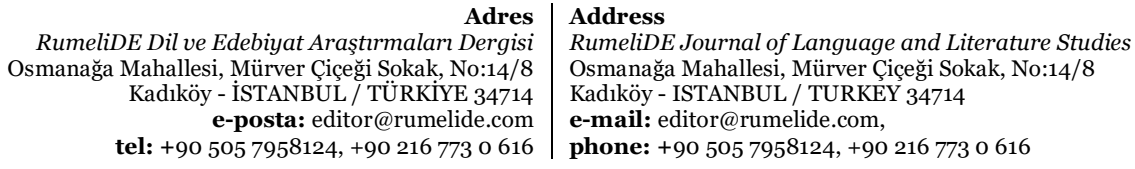


Kongar, Emre (1999), Kültür Üzerine, 6.bs. İstanbul: Remzi Kitapevi.

Peck, D. (1998). Teaching culture: Beyond language. Yale: New Haven Teachers Institute.

Soyşekerci, G. (2015). İngilizce ve Türkçe Ders Kitaplarında Kültürel Ögelerinin İncelemesi. Yayımlanmamış Yüksek Lisans Tezi, Dokuz Eylül Üniversitesi, Eğitim Bilimleri Enstitüsü, İzmir.

Ülker, N. (2007). Hitit Ders Kitapları Örneğinde Yabancı Dil Olarak Türkçe Öğretiminde Kültür Aktarımı Sürecine Çözümleyici ve Değerlendirici Bir Bakış. Yayımlanmamış Yüksek Lisans Tezi, İstanbul Üniversitesi Sosyal Bilimler Enstitüsü.

RumeliDE Dil ve Edebiyat Araştırmaları Dergisi Osmanağa Mahallesi, Mürver Çiçeği Sokak, No:14/8 Kadıköy - ÍSTANBUL / TÜRKIYE 34714 e-posta: editor@rumelide.com tel: +90 $5057958124,+902167730616$
Address

RumeliDE Journal of Language and Literature Studies Osmanağa Mahallesi, Mürver Çiçeği Sokak, No:14/8

Kadıköy - ISTANBUL / TURKEY 34714

e-mail: editor@rumelide.com

phone: +90 505 7958124, +90 2167730616 